\title{
CARTOX 10 Point Neurological Assessment
}

National Cancer Institute

\section{Source}

National Cancer Institute. CART OX 10 Point Neurological Assessment. NCI Thesaurus.

Code C155295.

A test to monitor for neurotoxicity related to CAR T therapy: orientation to year, month, city, hospital, and President; ability to name 3 specified objects; ability to write a standard sentence; ability to count backwards from 100 by 10 . 